\title{
上海に於け弓防火用水槽內蚊族幼虫の発生狀況 附元の幼虫撲滅に関する実験成績
}

\author{
門 馬健 次・高 橋多蔵 \\ 上海:同仁会華中防疫処等生虫举:部
}

\begin{abstract}
NOTES ON THE OCCURRENCE OF MOSOUITO LARVAE IN WATER-TANKS IN SHANGHAI AND AN EXPERIMENTAI, RESULT ON THE DESTRUCTION OF THE LARVAE
\end{abstract}

KenJI MOMMA and Tazô TAKAHASHI

Division of Parasitology, Dojin kiri Health Center, Shanghai, Central China

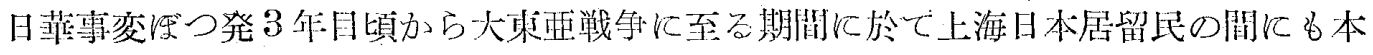

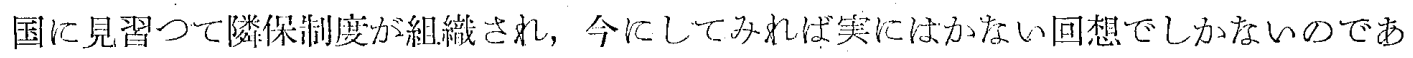

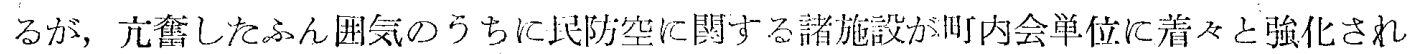

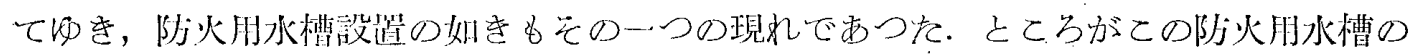

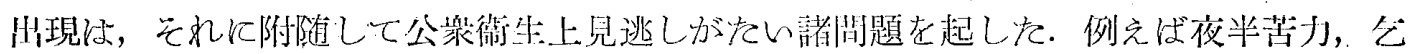

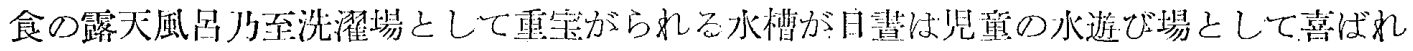

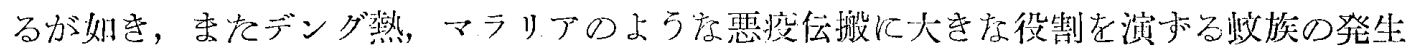

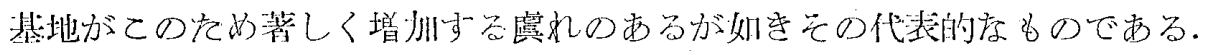

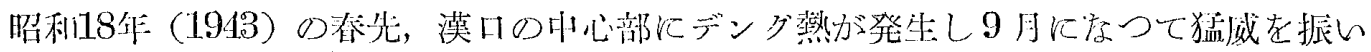

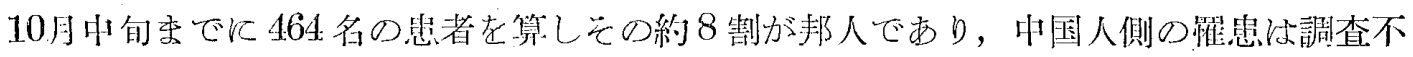

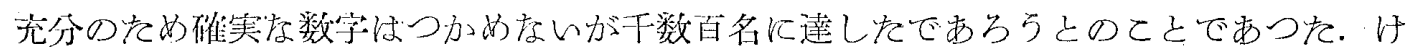

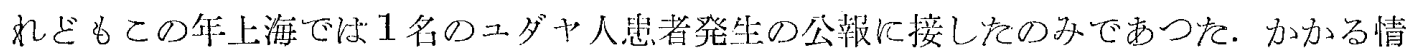

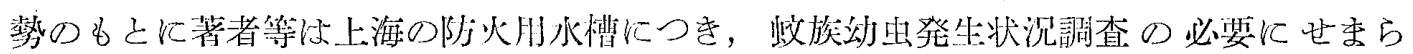

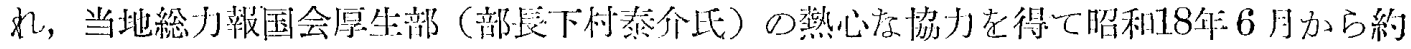

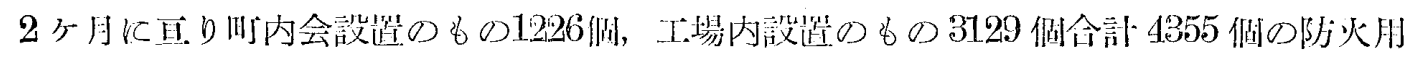

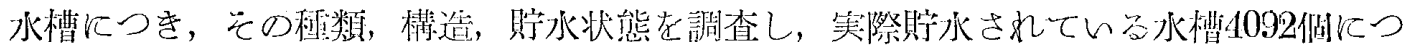

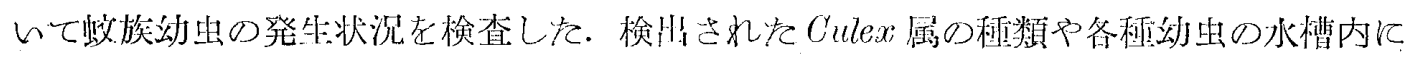

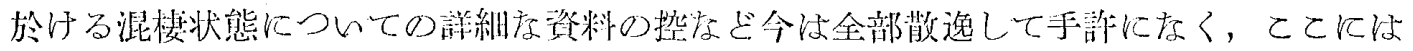
Anopheles hyrcanus var. sinensis \& Aedes allopictus 02 種についての办記述するの

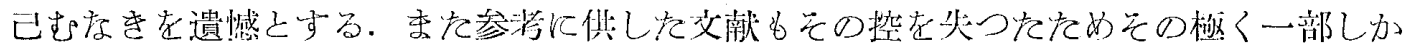
ここに载せるととができ席い。

\section{調查地区之水橧の種類}

次に示す調査地区の地図と第1表，第2表々を参留せら玌をい， 


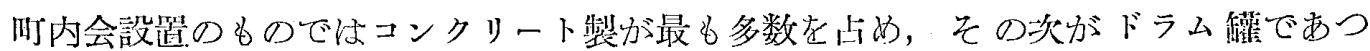

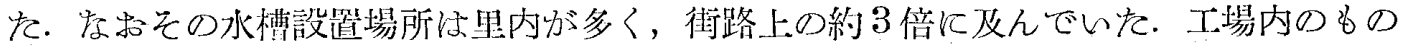

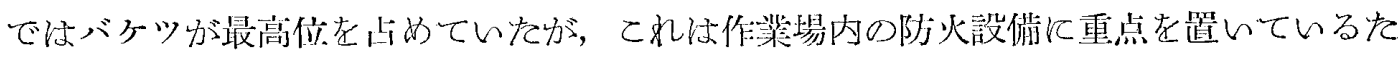

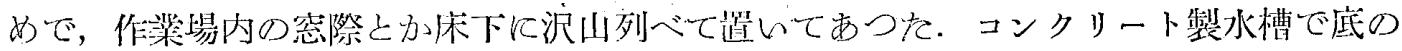

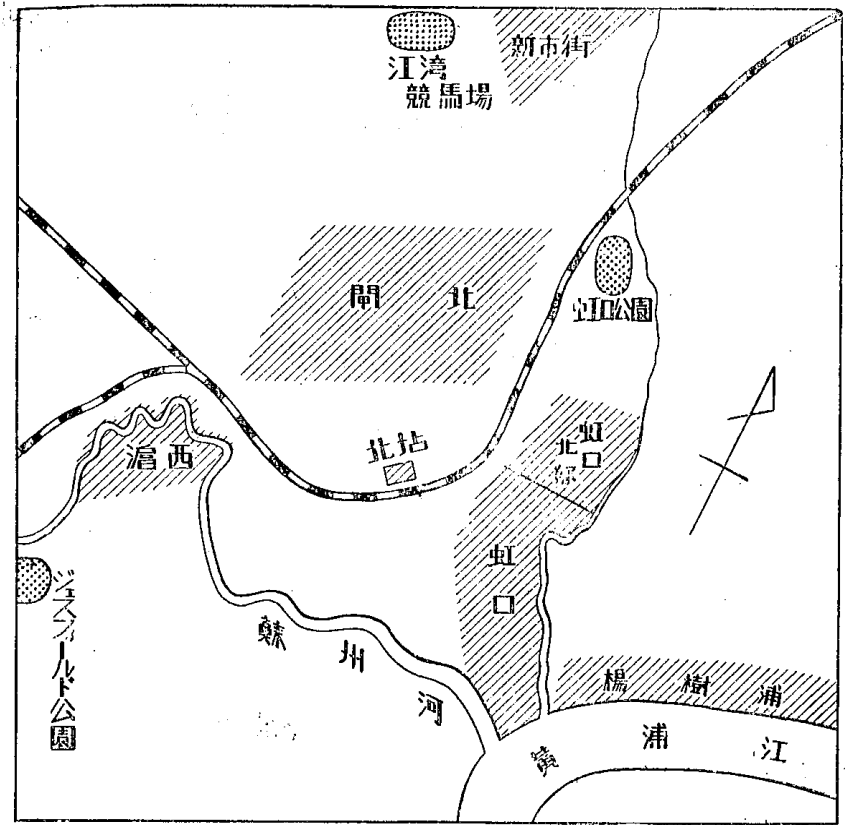

上海に肪ける調査地区心咯図

矣 1 瑟: 調查地区と調查水槽数

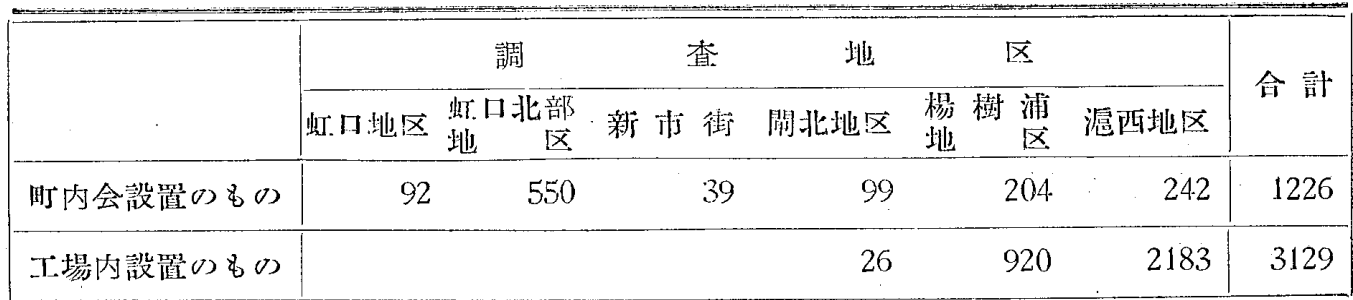

笨 2 表. 調查した水槽の種類

\begin{tabular}{|c|c|c|c|c|c|c|c|}
\hline & 水 & 槽 & $\sigma$ & 種 & & 類 & \\
\hline & $\begin{array}{l}コ \vee ク \\
\text { リート龁 }\end{array}$ & ドラム鑵 & 繁 & 陶 & 器 & バォツ & D \\
\hline 町内会設置のもの & 460 & 413 & 24.4 & & 99 & 10 & 1226 \\
\hline 工埸内設置のもの & 8 & 433 & 58 & & 1 & 2629 & 3129 \\
\hline
\end{tabular}

造りに，合理的度工夫の施されているものが汪とんに゙存く，水排口にむかつて底面に傾

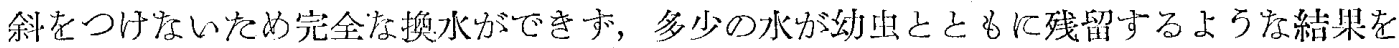

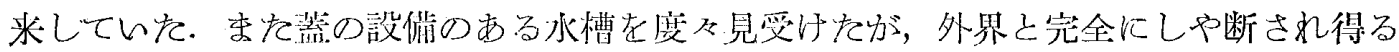

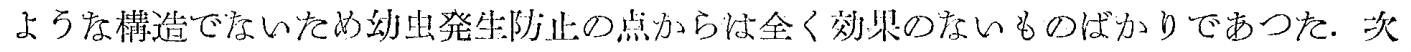




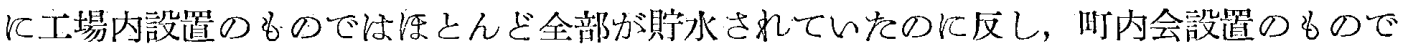

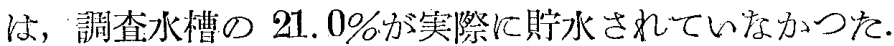

\section{蚊族幼虫の発生狀況}

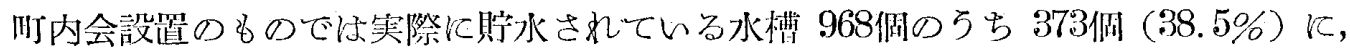

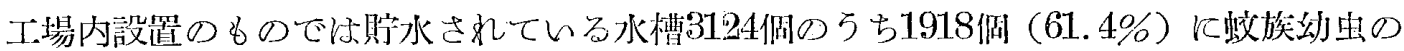

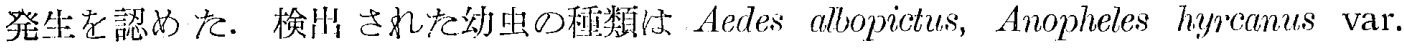

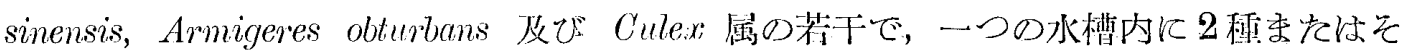

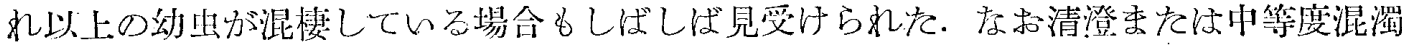

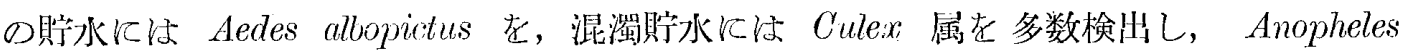

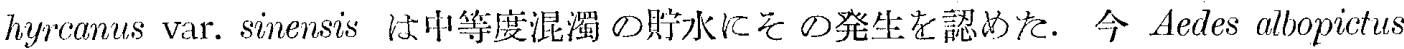
之 Anopheles hyrcanus var. sinensis の2種類だけについて観察する之, それら幼虫の検 州されを水槽の頻度法第3 表, 第4 表汇示与通りである。

第 3 表. 政族幼出発生水槽に対する Aedes albotichus 幼出檢出水槽の百分率

\begin{tabular}{|c|c|c|c|c|c|c|c|}
\hline & & \multicolumn{2}{|c|}{ 調 } & 查 & 地 & 区 & \\
\hline & & 㴔西 & 虾口 & 虹口北部 & 楊樹浦 & 開 北 & 新市街 \\
\hline 町内会設罪水槽の場合 & 30.6 & 44.0 & 42.9 & 24.3 & 23.2 & 13.7 & 0 \\
\hline 工場内設置水槽の堤合 & 88.2 & 90.3 & & & 87.8 & 7.1 & \\
\hline
\end{tabular}

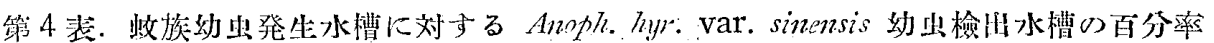

\begin{tabular}{|c|c|c|c|c|c|c|c|c|c|c|}
\hline & & \multicolumn{4}{|c|}{ 調 } & 查 & 地 & \multicolumn{2}{|r|}{ 区 } & \multirow[b]{2}{*}{ 変市街 } \\
\hline & & & 西 & 虾: & 酌 & 顸口北部 & 楊樹浦 & 開 & 北 & \\
\hline 町内会設置水旉の場合 & 0.6 & & 0.8 & & 0 & 0 & 0 & & $2: 0$ & 3.6 \\
\hline 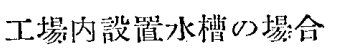 & 0.1 & & 0.1 & & & 0 & 0 & & & \\
\hline
\end{tabular}

かよらにして著者等は邦人密集地带である虾口，虹口北部の雨䟝区及び集团坐活を営 む工場内に，特に Aedes albopictus の多数発生している事寒を倠的ることができをので

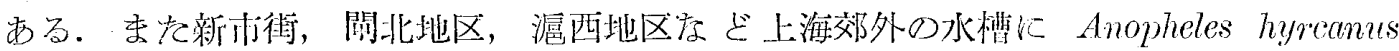

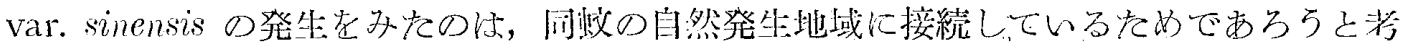

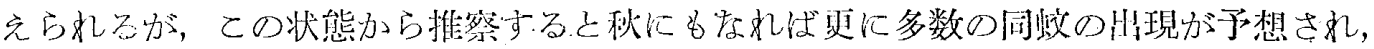

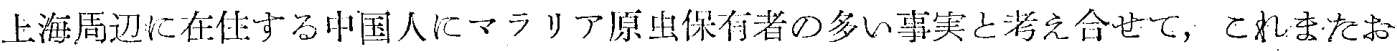

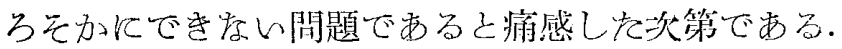

\section{附，蚊族幼虫㩰隇に関する実驗成績}

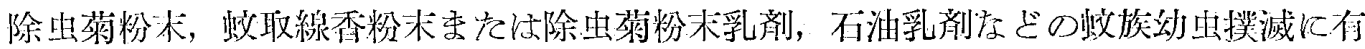

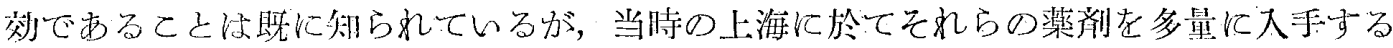


ことは現物の不足と高健格とのため非常に困難であつた，従つて著者等は容易に入手で

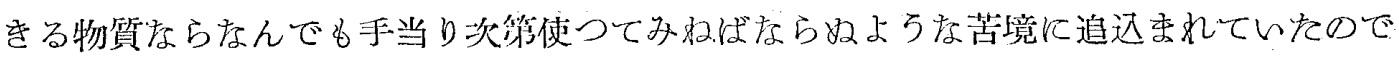
あるが，丁度その際偶及，多分ガス会社からであうたと記憶するが，不炭乹溜時その副 廉物之して生和るタール様物質を極内て容易に，しがも多量に大手するてとができたの

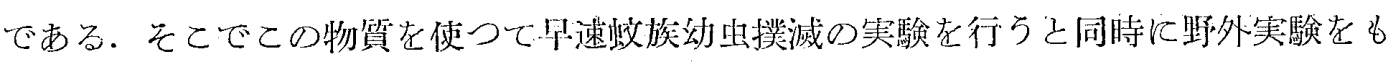

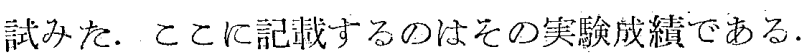

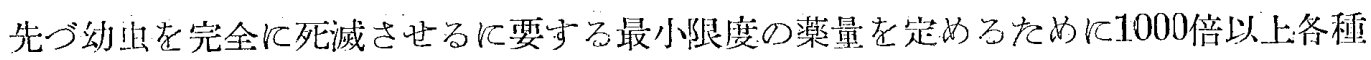

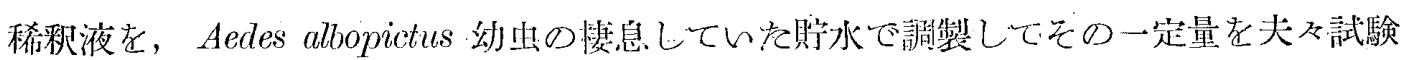

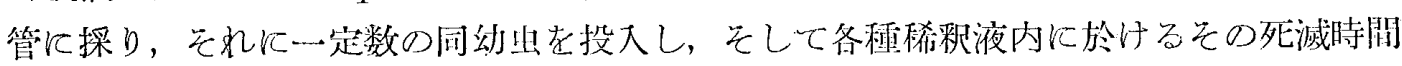
を測定した。第5表以前述の実験を数回繰返えして得を成續である。

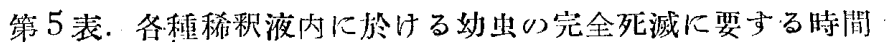

\begin{tabular}{|c|c|c|c|c|c|c|c|c|}
\hline & $\begin{array}{l}1000 \text { - } \\
2500 \text { 倍 }\end{array}$ & $\begin{array}{l}3000 \text { - } \\
3500 \text { 倍 }\end{array}$ & $\begin{array}{r}4000- \\
4500 \text { 倍 }\end{array}$ & $\begin{array}{l}5000 \text { - } \\
6500 \text { 倍 }\end{array}$ & $\begin{array}{c}7000- \\
7500 \text { 倍 }\end{array}$ & $\begin{array}{l}8000- \\
8500 \text { 倍 }\end{array}$ & $\begin{array}{l}9000 \text { - } \\
9500 \text { 倍 }\end{array}$ & 10,000 倍 \\
\hline $\begin{array}{l}\text { 死減に } \\
\text { 要-する } \\
\text { 時闻 }\end{array}$ & $\begin{array}{c}2 \\
\text { 時閪 }\end{array}$ & $\begin{array}{r}2-3 \\
\text { 時間 }\end{array}$ & $\begin{array}{c}4 \\
\text { 時䦩 }\end{array}$ & $\begin{array}{l}4-6 \\
\text { 時聞 }\end{array}$ & $\begin{array}{l}6 \\
\text { 洔閪 }\end{array}$ & $\begin{array}{l}6 \\
\text { 時墹 }\end{array}$ & $\begin{array}{l}10 \\
\text { 時闻 }\end{array}$ & $\begin{array}{l}10 \\
\text { 時間 }\end{array}$ \\
\hline
\end{tabular}

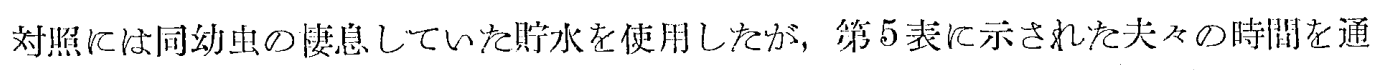

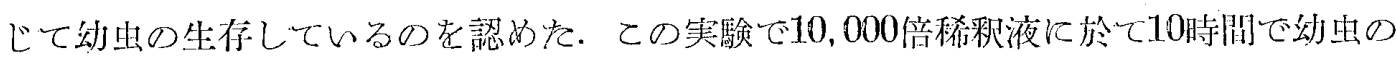
完全に死滅するてとを知つを.

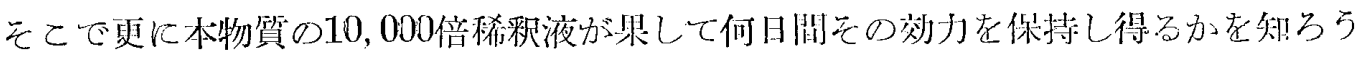

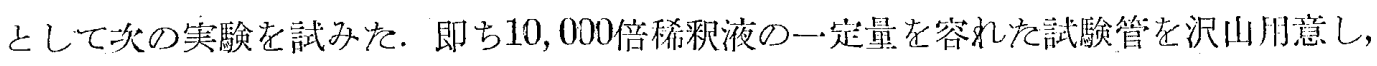
同稀釈液の経過日数别に每日 Aedes albopictus 幼虫の一定数を投大して，その完全死減

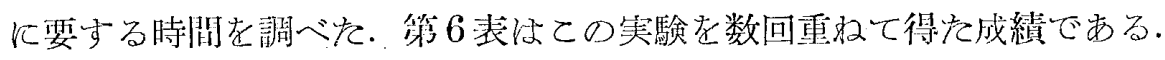

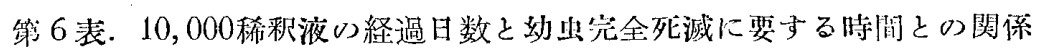

\begin{tabular}{|c|c|c|c|c|c|c|}
\hline & 稀 & 䣋 液 調 製 当 & 日よ & り & 過 日 & 数 \\
\hline & 調製当日 & 第 3 日 第 5 日 & 筷8 日 & 第 10 日 & 第 12 日 & 第 14 日 \\
\hline $\begin{array}{l}\text { 幼出の完全死滅 } \\
\text { に要する時間 }\end{array}$ & 10 時間 & 10 㭙間 & 24時閣 & 24 時閣 & 24時間 & 48 時間 \\
\hline
\end{tabular}

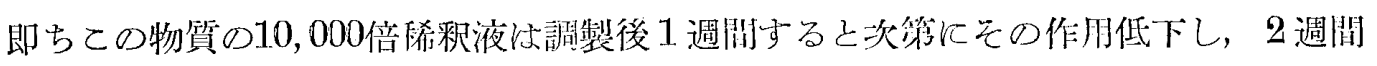

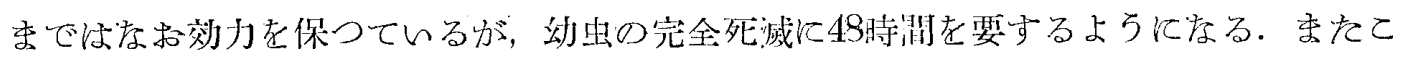

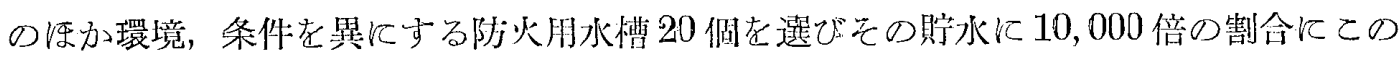
物質を混大し，その貯水中に小型昆虫採集網様のガーゼ袋を扱大して，そのなかで前記 同様の実験を野外で試多を。その結果によると, 換水直後の清澄な貯水に於て忧混濁委

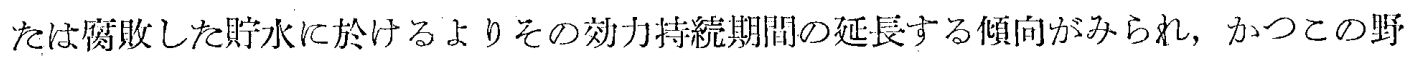
外実験でなの效力持続期間が前述の試験管内実験で得を記録14日䦌より更に長く24日

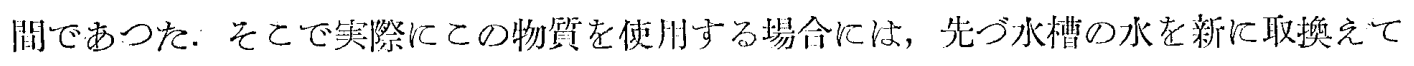


から本物筫を10,000倍の割合に混じ，次にその效力の消失しかける3 週閒日頃に更に本

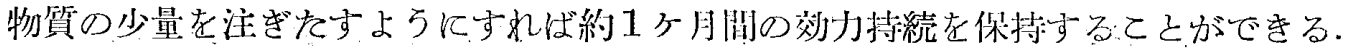

か上万にして昭和 18, 19 の雨年の夏は, 防火用水槽内の忟族幼出発生防止対策乙し て，前記野外実験の結果により知り得を倠效疗使朋法を指示しを注意書を添えて，ての 物質を上海自警村本部の手老経て冬叮内会一院布して。

ところが，かかる対策の実施中炤和19年是デング熱の集団発生が虾口地区の邦人阔に

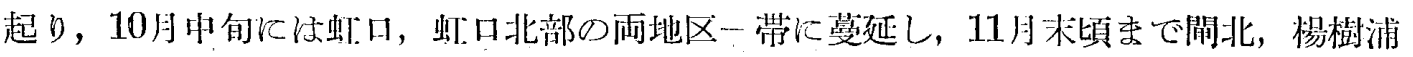

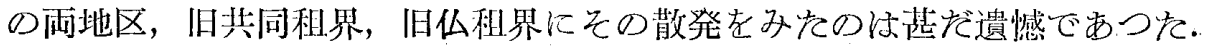

文

Loh, V.T. An epidemic of Dengue-like fever in Shanghai in 1940.

China Med. J. 60, 388--392. 1941.

門馬 健次 昭和19年夏発生した上海のデング

\section{献}

䓡に就いて，中支調查資料744号， 文化資料100号，1945年6月.

守山 英雄 1940 年上海に流行せるデング熱に 就て,上海自然科学研究所黄報 10 , 143-161. 1941年. 